\title{
UM ESTUDO SOBRE SÍNDROME DO BURNOUT EM FUNCIONÁRIOS DE AGÊNCIA BANCÁRIA DA CIDADE DE JUAZEIRO-BA
}

\author{
Leonardo de Oliveira Ferreira ${ }^{1}$, Juliana Farias Pereira ${ }^{2}$, Ralily Maria Lúcio Santos ${ }^{3}$, Gleice \\ Louise Silva Dantas ${ }^{4}$, Fernanda Roda de Souza Araújo Cassundé 5
}

\begin{abstract}
Resumo
Este artigo teve como objetivo analisar os níveis de Burnout individuais e total em uma agência bancária de economia mista situada na cidade de Juazeiro-BA. A pesquisa se qualifica de natureza quantitativa, e os dados foram obtidos através de questionário MBI-GS de Maslach, preenchido por 23 funcionários. O questionário procura analisar três aspectos psicologicamente correlacionados, sendo eles a Exaustão Emocional, o Cinismo e a Eficácia no Trabalho que, após a análise estatística, fornecem o índice do nível de Burnout. Os resultados obtidos demonstraram que apesar dos altos índices de Burnout conhecidos nas agências bancárias, é possível criar um ambiente de trabalho favorável e inclusivo, onde existam baixas taxas de exaustão e cinismo aliadas a uma alta eficácia no trabalho.
\end{abstract}

Palavras-chave: Burnout. Agência bancária. Exaustão

\section{A STUDY ABOUT THE BURNOUT SYNDROME IN EMPLOYEES OF A BANKING AGENCY AT JUAZEIRO-BA}

\begin{abstract}
This article aims to analyze the individual and total burnout levels in a bank of mixed economy in the city of Juazeiro-BA. The research describes as quantiqualitative nature, and the data was obtained through a questionnaire MBI- GS Maslach, filled by 23 employees. The survey analyzes three psychologically related aspects that after statistical analysis, providing content level of Burnout: Emotional Exhaustion, Cynicism and the Effectiveness at Work. The results showed that despite the high levels of Burnout known in bank branches, you can create a supportive and inclusive work environment, where there are low exhaust rates and cynicism combined with a high efficiency at work.
\end{abstract}

Keywords:Burnout. Bank branch. Weariness.

\footnotetext{
${ }^{1}$.Estagiário no Projeto Comércio e Serviços do Sertão do São Francisco- SEBRAE/PE

Docente em Língua Estrangeira no Complexo Educacional ECCOS

${ }^{2}$.Graduanda em Administração pela UNIVASF- Universidade Federal do Vale do São Francisco

${ }^{3}$ Assistente Administrativo Tributário na Prefeitura Municipal de Jaguarari/BA.

Graduanda em Administração pela UNIVASF- Universidade Federal do Vale do São Francisco

${ }^{4}$.Bolsista de nível superior no Banco do Nordeste do Brasil S/A - BNB

Graduanda em Administração pela UNIVASF- Universidade Federal do Vale do São Francisco

${ }^{5}$.Professora Adjunta I/Colegiado de Administração da UNIVASF - Universidade Federal do Vale do São

Francisco. Autor correspondente: Fernanda.roda@univasf.edu.br.
} 


\section{Introdução}

Algumas pessoas têm um sonho de superar a concorrência de um concurso para fazer parte do quadro de funcionários em um banco de economia mista e desfrutar de todos os benefícios que trazem a remuneração destes cargos. Porém este ambiente pode se revelar com altos níveis de estresse, causando danos à saúde destes profissionais.

Naturalmente as preocupações de doenças do trabalho são direcionadas ao esforço físico e repetitivo, porém existem os fatores silenciosos e que tem impacto sobre a autoestima e o equilíbrio emocional, estes fatores provem de ambientes com ritmos intensos de trabalho e pressões psicológicas, e estes são propícios a se desenvolverem na atividade bancária.

A constante pressão, principalmente aquelas envolvendo o alcance de metas, pode desencadear outros tipos de doenças psicopatológicas mais graves, como síndrome do pânico, transtornos obsessivos compulsivos, depressão e o burnout, que é o objeto desta pesquisa.

De origem inglesa, o termo burnout é derivado da junção de dois termos: burn e out, que significam respectivamente queimar e fora. Expressões que também podem ser traduzidas como "ser consumido pelo fogo". Para autores como Malasch (2003), essa síndrome é decorrente da exaustão emocional, isto é, quando o indivíduo sente suas energias e forças consumidas. O Burnout é o estado de tensão emocional e estresse já em sua fase crônica, e que geralmente afetam os profissionais que lidam intensamente com o público em atividades que influenciam diretamente em suas vidas (MUROFUSE; ABRANCHES; NAPOLEÃO, 2005; SCHUSTER; DIAS; BATTISTELLA, 2015). Importa dizer que a Síndrome de Burnout está diretamente relacionada com o mundo do trabalho, com o tipo de atividade laboral do indivíduo. Está presente na Síndrome de Burnout aspectos sociais, inter-relacionais, através da despersonalização, o que não necessariamente ocorre no estresse ocupacional (MASLACH; LEITER, 1999). Nesse sentido, percebe-se que a Síndrome de Burnout e o Estresse ocupacional compartilham de duas características, a exaustão emocional e perda da realização profissional, no entanto, o que as diferencia é a despersonalização, característica presente apenas na Síndrome de Burnout.

Nesse contexto, este estudo é guiado pela seguinte pergunta de pesquisa: "Qual o índice de Burnout entre os funcionários de uma agência bancária de economia mista na cidade de Juazeiro-BA?". Este estudo se justifica em razão da necessidade de proporcionar aos colaboradores um ambiente de trabalho adequado e harmonioso, tendo em vista a nova perspectiva da Gestão Estratégica de Pessoas, que se preocupa com ações que visam à 
qualidade de vida, saúde e segurança no trabalho a fim de assegurar a eficácia e a eficiência nos resultados organizacionais.

\section{Metodologia}

O presente estudo caracteriza-se como uma pesquisa de natureza quantiqualitativa, utilizando-se do questionário Maslach Burnout Inventory - Genereal Survey (MBI-GS), sendo este amplamente utilizado para a mensuração do nível de Burnout nos contextos trabalhistas e ocupacionais (MASLACH; SCHAUFELI; LEITER, 2001; SCHUSTER et al, 2015).

O questionário se apresenta subdividido em três aspectos distintos, porém correlacionados psicologicamente, sendo estes caracterizados como Exaustão Emocional, aqui denominada de EE, referindo-se ao esgotamento de energia emocional e à fadiga do colaborador, porém sem ligação direta com a origem da situação apresentada. Esta dimensão é mensurada através de seis variáveis. O segundo quesito diz respeito ao Cinismo, aqui apresentado como CI, e discorre sobre a sensação de indiferença ou atitude que torne o colaborador distante do trabalho; este quesito contém quatro variáveis. Por fim, têm-se a Eficácia no Trabalho, chamada de ET, que dá maior ênfase as expectativas do indivíduo em relação à sua ocupação.

Para a mensuração de frequência de ocorrência das variáveis, utilizou-se uma escala Likert de 5 pontos, como sugerida por Alexandre (2003). Desta forma, as frequências encontram-se entre 1 e 5, variando de nunca, anualmente, mensalmente, semanalmente e diariamente.

$\mathrm{Na}$ escala de Likert as respostas para cada item variam de acordo com o grau de intensidade. Essa escala com categorias ordenadas, igualmente espaçadas e com mesmo número de categorias em todos os itens, é largamente utilizada em pesquisas organizacionais que investigam as práticas de Burnout.

As dezesseis variáveis analisadas neste estudo, validadas e adaptadas para o português por Fonte (2011),são apresentadas no Quadro 1.

Os escores serão obtidos através da média aritmética, e nos itens EE e CI, quanto mais alto o índice, maior o nível de estresse. Quanto às variáveis de ET, a relação se demonstra inversamente proporcional, pois quanto menor a frequência, maior o nível de estresse, devido à baixa eficácia no trabalho. Para efeitos de análise, a escala desta seção será invertida para oferecer resultados homogêneos. 
Baseado no estudo de Telles e Pimenta (2009), foi realizada também uma análise dos dados procurando uma correlação entre as variáveis de idade, sexo, tempo de serviço e grau de escolaridade. Estas perguntas foram inseridas ao final do questionário MBI-SG.Esta correlação foi obtida a partir de um cruzamento entre o índice total do nível de estresse em cada questionário e as variáveis qualitativas apresentadas, observando a frequência das mesmas.

Quadro 1: Variáveis por fator de Burnout MBI-GS

\begin{tabular}{|c|c|}
\hline Código & Variável \\
\hline EE 1 & Sinto-me emocionalmente esgotado com o meu trabalho \\
\hline EE 2 & Sinto-me esgotado no final de um dia de trabalho \\
\hline EE 3 & $\begin{array}{l}\text { Sinto-me cansado quando me levanto pela manhã e preciso encarar } \\
\text { outro dia de trabalho }\end{array}$ \\
\hline EE 4 & Trabalhar o dia todo é realmente motivo de tensão para mim \\
\hline EE 5 & Sinto-me acabado por causa do meu trabalho \\
\hline EE6 & Só desejo fazer meu trabalho e não ser incomodado \\
\hline CI 1 & $\begin{array}{l}\text { Sou menos interessado no meu trabalho desde que assumi essa } \\
\text { função }\end{array}$ \\
\hline CI 2 & Sou menos entusiasmado com o meu trabalho \\
\hline CI 3 & Sou mais descrente sobre a contribuição de meu trabalho para algo \\
\hline CI 4 & Duvido da importância do meu trabalho \\
\hline ET 1 & Sinto-me entusiasmado quando realizo algo no meu trabalho \\
\hline ET 2 & Realizo muitas coisas valiosas no meu trabalho \\
\hline ET 3 & $\begin{array}{l}\text { Posso efetivamente solucionar os problemas que surgem no meu } \\
\text { trabalho. }\end{array}$ \\
\hline ET 4 & $\begin{array}{l}\text { Sinto que estou dando uma contribuição efetiva para essa } \\
\text { organização. }\end{array}$ \\
\hline ET 5 & Na minha opinião, sou bom no que faço. \\
\hline ET 6 & $\begin{array}{l}\text { No meu trabalho, me sinto confiante de que sou eficiente e capaz de } \\
\text { fazer com que as coisas aconteçam. }\end{array}$ \\
\hline
\end{tabular}

Fonte: Fonte (2011)

Importa destacar que foram analisadas as médias para cada questionário, bem como as médias individuais dentro de cada aspecto (EE, CI e ET). Após essa fase foi calculada uma média geral para sintetizar o nível de Burnout de cada funcionário.

Visando tornar mais claros os resultados, foi elaborado o Quadro 2 apresentando os níveis de Burnout divididos em baixo, intermediário e alto, de acordo com a metodologia utilizada por Mclaurine (2008). 
Quadro 2: Níveis de Burnout

\begin{tabular}{|ll|}
\hline Nível & Escala \\
Baixo & $>2,33$ \\
Moderado & $2,34-3,67$ \\
Alto & $3,67<$ \\
\hline
\end{tabular}

Fonte: Adaptado de Mclaurine (2008)

A respeito da unidade de análise, é possível dizer que a instituição bancária é uma empresa estatal, caracterizada por uma sociedade de economia mista e capital aberto, controlada pelo Governo Federal Brasileiro.Possui uma rede de 273 agências, que aliadas aos trabalhos dos Agentes de Desenvolvimento e das Agências Itinerantes, permitem que o Banco esteja presente em cerca de 2 mil municípios em sua área de atuação, que contempla todos os Estados do Nordeste, e os nortes de Minas Gerais e do Espírito Santo.A agência escolhida está localizada na cidade de Juazeiro/BA e considerou o critério de acessibilidade dos pesquisadores. Por motivos de confidencialidade de registros teve sua identificação suprimida.

Os sujeitos participantes do estudo foram os funcionários da agência escolhida. De 26 colaboradores, 24 preencheram o termo de consentimento para participação no estudo. Em razão de um preenchimento erronêo do instrumento de coleta de dados, foram totalizados 23 questionários válidos para análise.

A coleta de dados ocorreu durante o primeiro trimestre de 2016.

\section{Resultados e Discussão}

O trabalho é resultado de esforço, de dispêndio de energia física e mental, produz bens e serviços, além de satisfazer as necessidades individuais e o bem-estar pessoal, contribuindo para manutenção e desenvolvimento da sociedade como um todo (ARAÚJO et al., 2003). Trabalhar tornou-se uma condição essencial, visto que sua importância não está apenas ligada à questão econômico-financeira, é também um meio de realização e desenvolvimento pessoal.

Vale a pena destacar que Codo; Sampaio e Hitomi (1993, p. 59) enfatizam que "tentar compreender o homem sem considerar o trabalho é tentar compreender o homem, apesar de sua vida", assim percebe-se que o trabalho é inerente ao homem, isto é, faz parte da sua própria sobrevivência. Para Fernandes et al. (2008), o trabalho é parte da construção da identidade dos indivíduos, sendo considerado um processo de criação e não somente uma 
fonte de sustento. Assim, ele ocupa um papel central na vida das pessoas, pois é através dele que o ser humano forma sua identidade, encontra meio de sobrevivência, qualidade de vida que é proporcionada pela satisfação de condições objetivas como a renda, qualidade de habitação, segurança, privacidade e afeto, como também realização pessoal, elevação da autoestima e da motivação, e reconhecimento social.

Neste contexto, considera-se que para o homem alcançar o bem estar, ele necessita de um equilíbrio entre as expectativas criadas em relação à atividade profissional e à realização das mesmas, fator que constituem a qualidade de vida. Assim, é fundamental possuir uma relação satisfatória com o trabalho, pois é um meio de desenvolvimento para as diferentes áreas da vida, quer seja pessoal, social e profissional.

Então, para que o individuo mantenha o equilíbrio entre as expectativas e a atividade profissional, ele precisara de apoios afetivos (que provém de relacionamentos com pessoas íntimas e de confiança), e apoios sociais (provém das relações gerais estabelecidas naturalmente, como por exemplo, os colegas de trabalho). Quando tais apoios são ausentes, o indivíduo pode ser levado à fragilidade emocional simplesmente pelo fato de não ter com quem compartilhar suas preocupações, anseios e problemas, que atrelado às pressões no ambiente de trabalho, gera uma tensão emocional, podendo gerar um estresse ocupacional e/ou a síndrome de Burnout.

Nesse sentido, com o objetivo de analisar os níveis de Burnout dos funcionários da agência bancária foi elaborado o Quadro 3, que apresenta os resultados dos níveis de Burnout para cada respondente.

De acordo com as as médias de EE, ou seja, exaustão emocional, obteve-se resultados que variam de 1,3 até 4,33, achando sua média em 2,70. Assim, foi comprovado um nível moderado de exaustão emocional nos funcionários da instituição. Quando analisados os níveis de CI, cinismo, de uma maneira contrária, os níveis vão de 1 até 3,5, com média em 1,28, caracterizando-se como baixo nível de cinismo. Ao final das análises especificas, o ET foi estudado -tendo suas médias invertidas pelo aspecto positivo dos questionamentos- com resultados entre 1,0 e 2,83, com média de 1,28, também apresentando alto nível de eficácia no trabalho.

Corroborando com dados encontrados por Telles e Pimenta (2009) e Schuster et al. (2014), os níveis de exaustão emocional se encontram maiores do que as médias em geral, indicando que o setorestá mais suscetível a exaustão em detrimento do cinismo ou baixa eficácia no trabalho. 
Quadro 3: Níveis de Burnout para cada respondente

\begin{tabular}{|ccccc|}
\hline Questionário & Média EE & Média CI & Média ET & Média Burnout \\
$\mathbf{1}$ & 1,33 & 1,0 & 1,0 & 1,12 \\
$\mathbf{2}$ & 1,5 & 1,0 & 1,0 & 1,19 \\
$\mathbf{3}$ & 1,5 & 1,0 & 1,0 & 1,19 \\
$\mathbf{4}$ & 1,5 & 1,0 & 1,33 & 1,31 \\
$\mathbf{4}$ & 1,67 & 1,0 & 1,0 & 1,37 \\
$\mathbf{6}$ & 2,0 & 1,25 & 1,0 & 1,44 \\
$\mathbf{7}$ & 2,17 & 1,0 & 1,0 & 1,44 \\
$\mathbf{8}$ & 2,17 & 1,0 & 1,0 & 1,44 \\
$\mathbf{9}$ & 1,67 & 1,0 & 1,83 & 1,56 \\
$\mathbf{1 0}$ & 2,67 & 1,0 & 1,0 & 1,62 \\
$\mathbf{1 1}$ & 3,0 & 1,0 & 1,17 & 1,81 \\
$\mathbf{1 2}$ & 2,5 & 2,0 & 1,17 & 1,88 \\
$\mathbf{1 3}$ & 3,33 & 1,0 & 1,0 & 1,88 \\
$\mathbf{1 4}$ & 2,83 & 1,0 & 1,67 & 1,94 \\
$\mathbf{1 5}$ & 2,83 & 1,0 & 1,83 & 2,0 \\
$\mathbf{1 6}$ & 4,0 & 1,0 & 1,0 & 2,12 \\
$\mathbf{1 7}$ & 2,83 & 2,5 & 1,33 & 2,19 \\
$\mathbf{1 8}$ & 4,17 & 1,25 & 1,0 & 2,25 \\
$\mathbf{1 9}$ & 4,17 & 1,0 & 1,33 & 2,31 \\
$\mathbf{2 0}$ & 3,83 & 2,25 & 1,0 & 2,44 \\
$\mathbf{2 1}$ & 4,33 & 1,5 & 1,67 & 2,62 \\
$\mathbf{2 2}$ & 3,6 & 3,5 & 1,5 & 2,62 \\
$\mathbf{2 3}$ & 3,17 & 3,5 & 1,5 & 2,69 \\
Média Final: & $\mathbf{2 , 7 0}$ & $\mathbf{1 , 3 4}$ & $\mathbf{1 , 2 8}$ & $\mathbf{1 , 8 4}$ \\
\hline
\end{tabular}

Fonte: elaboração dos autores

A pesquisa de campo registra que $83 \%$ dos funcionários apresentam baixo nível de Burnout, $17 \%$ níveis moderados e, nenhum funcionário com níveis altos da síndrome. Esta análise, que vai no sentido oposto do senso comum, comprova que apesar dos altos índices de Burnout conhecidos nas agências bancárias, é possível criar um ambiente de trabalho favorável e inclusivo, onde existam baixas taxas de exaustão e cinismo aliadas a uma alta eficácia no trabalho.

Pode-se inferir que a agência bancária apresenta diversos fatores que geram estresse em todos os funcionários, e que à demanda excessiva de clientes ocasiona desconforto aos funcionários. Assim tem-se que é necessário observar os fatores que trazem desconforto a seus funcionários para evitar possíveis doenças psicológicas como a Síndrome de Burnout.

A fim de analisar melhor quais os fatores mais pontuados pelos funcionários ao se tratar de estresse ocupacional, foi extraída uma média entre todos os questionários para cada item apresentado, no quadro abaixo. 
Quadro 4: Médias totais por variáveis

\begin{tabular}{|c|c|c|}
\hline Código & Variável & $\begin{array}{c}\text { Média } \\
\text { Geral }\end{array}$ \\
\hline EE 1 & Sinto-me emocionalmente esgotado com o meu trabalho & 2,82 \\
\hline EE 2 & Sinto-me esgotado no final de um dia de trabalho & 3,60 \\
\hline EE 3 & $\begin{array}{l}\text { Sinto-me cansado quando me levanto pela manhã e preciso } \\
\text { encarar outro dia de trabalho }\end{array}$ & 2,91 \\
\hline EE 4 & Trabalhar o dia todo é realmente motivo de tensão para mim & 2,3 \\
\hline EE 5 & Sinto-me acabado por causa do meu trabalho & 2,13 \\
\hline EE6 & Só desejo fazer meu trabalho e não ser incomodado & 2,48 \\
\hline CI 1 & $\begin{array}{l}\text { Sou menos interessado no meu trabalho desde que assumi } \\
\text { essa função }\end{array}$ & 1,21 \\
\hline CI 2 & Sou menos entusiasmado com o meu trabalho & 1,43 \\
\hline CI 3 & $\begin{array}{l}\text { Sou mais descrente sobre a contribuição de meu trabalho para } \\
\text { algo }\end{array}$ & 1,35 \\
\hline CI 4 & Duvido da importância do meu trabalho & 1,39 \\
\hline ET 1 & Sinto-me entusiasmado quando realizo algo no meu trabalho & 1,35 \\
\hline ET 2 & Realizo muitas coisas valiosas no meu trabalho & 1,35 \\
\hline ET 3 & $\begin{array}{l}\text { Posso efetivamente solucionar os problemas que surgem no } \\
\text { meu trabalho. }\end{array}$ & 1,43 \\
\hline ET 4 & $\begin{array}{l}\text { Sinto que estou dando uma contribuição efetiva para essa } \\
\text { organização. }\end{array}$ & 1,13 \\
\hline ET 5 & Na minha opinião, sou bom no que faço. & 1,26 \\
\hline ET 6 & $\begin{array}{l}\text { No meu trabalho, me sinto confiante de que sou eficiente e } \\
\text { capaz de fazer com que as coisas aconteçam. }\end{array}$ & 1,22 \\
\hline
\end{tabular}

Fonte: elaboração dos autores

Através da análise dos dados dados foi possível perceber que o ponto mais crítico ao se tratar de exaustão emocional foi o esgotamento ao final do dia do trabalho (EE2), quanto ao cinismo, a falta de entusiasmo é o item com maiores médias, porém, ainda assim são baixas (CI2), e na eficácia do trabalho, os funcionários sentem que não podem solucionar efetivamente os problemas que surgem no ambiente de trabalho (ET3). É possível notar que, mais uma vez, todas as médias de exaustão emocional são superiores aos demais aspectos da pesquisa.

No cruzamento de dados da amostra, análises mais sutis foram possíveis a medida que os resultados aparecem.

Os resultados obtidos no que tange ao sexo, foram bastante equilibrados, mostrando que, entre os 4 maiores índices de estresse, 2 pertencem a cada sexo. Esta análise deixa claro a falta de correlação com gênero no presente estudo, refutando a tese de Schuster et al. (2014). 
Ao que se relaciona o tempo, sendo este tanto de exercício da função quanto da idade, os resultados mais preocupantes apresentam apenas entre 1 e 2 anos de trabalho, tendo entre 20 e 30 anos. Sobre o grau de escolaridade, não foi possível achar correlação devido à grande disparidade entre as medias encontradas, não havendo padrão entre os mesmos, sendo identificado que os três maiores níveis pertencem a pessoas com médio completo, superior completo e superior incompleto.

Um fato interessante é de que o funcionário com maior tempo na organização apresenta o menor nível de Burnout encontrado, sendo 1,12, extremamente próximo do valor mínimo.

Nesse sentido, a partir dos achados da pesquisa empírica e da discussão com a literatura, é importante ressaltar que o surgimento dessa síndrome pode gerar várias conseqüências sobre o indivíduo e conseqüentemente sobre as organizações. Sobre os indivíduos pode-se citar consequiências físicas e mentais como:

Depressão - O sofrimento psíquico manifesta-se sob forma de depressão, tristeza e apatia que atingem o corpo e a alma Roudinesco (2000). Resumindo-se a uma sensação de ausência de prazer de viver, sentimentos de tristeza que afeta os pensamentos e o comportamento da pessoa. Estas podem ser breves, moderadas ou até graves;

Fadiga e irritabilidade- causado pelo excesso de trabalho, individuo sente esgotado fisicamente, sem forças e com baixa tolerância;

Sentimento de inutilidade - o individuo sente-se desqualificado para realizar suas atividades, visto que não sabe qual a finalidade e importância do seu trabalho para a organização;

Ansiedade, tensão nervosa e carga psicosensorial - relacionadas ao medo de errar, pois o individuo precisa usar bastante sua concentração e memorização, o que aumenta o sofrimento sentido;

Insatisfação - resultante do confronto entre as expectativas, desejos e os resultados.

Já as principais conseqüências que afetam as organizações negativamente são:

A baixa qualidade dos serviços - que é justamente devido à diminuição de afetividade do trabalhador, pois o trabalhador passa a tratar os receptores de seus serviços de com atitudes negativas, que deflagra uma deterioração na qualidade de seu serviço prestado;

$O$ Baixo desempenho - que é proveniente da fadiga, da exaustão emocional dos indivíduos, conseqüentemente apresentam baixos rendimentos, muitas vezes não executam suas tarefas corretamente, por falta de concentração, cansaço físico e mental, e ate devido à sentimentos depressivos, o que afeta a produtividade da organização. 
Absenteísmo - significa o hábito de não comparecer de estar ausente (BARBOZA; SOLER, 2003). A principal causa são os afastamentos por motivo de doença, afetados pelos sintomas da síndrome de Burnout os indivíduos tendem a se ausentar do trabalho. Esse tipo de doença psicológica afeta diretamente nos custos diretos e indiretos da organização, devido a redução da produtividade, e no caso dos serviços reduzirá a qualidade do serviço prestado, aumentara o estresse dos demais empregados como também as horas extras, ou até mesmo por falta de substituição, os serviços deixarem de ser realizados.

\section{Conclusões}

Da revisão de literatura nota-se que a Sindrome de Burnout não se restringe apenas a profissões ligadas à saúde e educação, sendo esta vista como um fenômeno que afeta praticamente todas as profissões, uma vez que a tendência atual é pensar em Burnout em profissões que possuem intenso e constante contato interpessoal (MASLACH; LEITER, 1999). Destaca-se este ponto pois, cada vez mais, as profissões têm exigido interrelações, seja no atendimento ao cliente, com colegas de trabalho e superiores, ou até mesmo pela forma de trabalho, envolvendo grupos e equipes nas realizações das atividades.

Da pesquisa de campo denota-se que apesar do aspecto Exaustão Emocional ter apresentado níveis altos, chegando a 4,33 em uma escala de 1 a 5, obteve-se o baixo nível de Burnout na maioria dos questionários graças aos baixos níveis de Cinismo e Eficácia no Trabalho, que se apresentaram em sua maioria na média mínima 1. Ou seja, apesar do cansaço psicológico e físico, os bancários ainda se sentem motivados, acham que contribuem significativamente e dão o melhor de si no exercício da sua função.

O alto nível no aspecto Exaustão Emocional pode estar relacionado à grande demanda por serviços no banco e ao grande fluxo de atendimentos, e não a fatores intrínsecos ao trabalhador, uma vez que a Eficácia no Trabalho apresentou a menor média entre os três aspectos.

Sendo assim, este estudo vai de encontro aos que comprovaram altos índices de estresse ocupacional em agências bancárias, mostrando que é possível minimizá-lo para otimizar o desempenho, a motivação e o sentimento de pertencimento do colaborador.

Como sugestão para novas pesquisas, pode-se aplicar a metodologia utilizada neste trabalho em uma agência bancária privada, ou em um banco de direito público, para realizar 
uma análise comparativa com o presente estudo, buscando identificar se a natureza jurídica da instituição influencia os resultados.

\section{Referências}

ALEXANDRE, J. et al. Análise do número de categorias da escala de Likert aplicada à gestão pela qualidade total através da teoria da resposta ao item. In: Encontro Nacional de Engenharia de Produção, 23, 2003, Ouro Preto, MG. Anais... Ouro Preto: Enegep, 2003.

ARAÚJO, T. M. et al. Estresse ocupacional e saúde: contribuições do Modelo Demanda Controle. Ciência \& Saúde Coletiva, v. 8, n. 4, p. 991-1003, 2003.

BARBOZA, D.B; SOLER, Z.A.S.G. Afastamento do trabalho na enfermagem: ocorrências com trabalhadores de um hospital de ensino. Revista Latino-Americana de Enfermagem, v.11, n. 2, p. 177-83, 2003.

CODO, W.; SAMPAIO, J. J. C.; HITOMI, A. H. Indivíduo, trabalho e sofrimento: uma abordagem interdisciplinar. Petrópolis, RJ: Vozes, 1993.

FERNANDES, J. D. et al. Saúde mental e trabalho: significados e limites de modelos teóricos. Revista Latino-Americana de Enfermagem, v. 14, n. 5. 2006. Disponível em: <http://www.eerp.usp.br/rlae>. Acesso em: 18 mar. 2016.

FONTE, C. M. S. Adaptação e validação para português do questionário de Copenhagen Burnout Inventory (CBI). Dissertação (Mestrado) - Faculdade de Economia da Universidade de Coimbra, Coimbra, Portugal, 2011.

MASLACH, C. Job burnout: New directions in research and intervention. Current Directions in Psychological Science, v. 12, n. 5, p. 189-192, 2003.

MASLACH, C.; LEITER, M.Fonte de Prazer ou Desgaste? Guia para vencer o estresse na empresa. Campinas: Papirus, 1999.

MASLACH, C.; SCHAUFELI, W.; LEITER, M. Job burnout. Annual review of psychology, v. 52, n. 1, p. 397-422, 2001.

MCLAURINE, W. D. A Correlational Study of Job Burnout and Organizational Commitment Among Correctional Officers. Dissertação (Mestrado) - Escola de Psicologia da Capella University, Minneapolis, Estados Unidos, 2008.

MUROFUSE, N.; ABRANCHES, S.; NAPOLEAO, A. Reflexões sobre estresse e Burnout e a relação com a enfermagem. Revista Latino-Americana de Enfermagem, v. 13, n. 2, p. 255-261, 2005.

ROUDINESCO, E. Por que a Psicanálise? Rio de Janeiro: Jorge Zahar Editor, 2000. 
SCHUSTER, M. et al. Identificação dos níveis de burnout em um hospital público e aplicação da escala mbi-gs. RAHIS, v. 11, n. 4, 2014.

SCHUSTER, M. S.; DIAS, V. V.; BATTISTELLA, L. F. Percepções de saúde e a síndrome de Burnout - aplicabilidade da MBI-GS. Revista de Carreiras e Pessoas, v. 5, n. 3, p. 380$391,2015$.

SCHUSTER, M. S. et al. Validação da escala MBI-GS: uma investigação General Survey sobre a percepção de saúde dos colaboradores. Revista de Gestão, v. 22, n. 3, p. 405-416, 2015.

TELLES, H.; PIMENTA, A. Síndrome de Burnout em agentes comunitários de saúde e estratégias de enfrentamento. Saúde e Sociedade, v. 18, n. 3, p. 467-478, 2009.

Recebido:04/04/2016

Aceito:03/07/2016 